\title{
IDENTIFICAÇÃO DE ELEMENTOS PARA CONSTRUCCÃO DO VOCABULÁRIO \\ CONTROLADO: CONTRIBUIÇÕES DO DIAGNÓSTICO DE ARQUIVO
}

\section{IDENTIFICATION OF ELEMENTS FOR CONSTRUCTION OF CONTROLLED VOCABULARY: CONTRIBUTIONS OF RECORDS SURVEY}

\author{
Maria Fabiana Izidio de Almeidaa \\ Walter Moreirab \\ Luciana Davanzoc \\ Marcia Cristina de Carvalho Pazin Vitoriano ${ }^{d}$
}

\begin{abstract}
RESUMO
Introdução: As organizações têm buscado o tratamento adequado de suas informações, isso perpassa a implantação da gestão de documentos, por meio dos seus instrumentos arquivísticos. Esta pesquisa fomenta discussões em torno de metodologia de diagnóstico de arquivo e construção de vocabulários controlados, atividades fundamentais para a implantação de uma gestão de documentos eficaz. Coloca-se como problema desta pesquisa: quais elementos devem ser identificados durante a realização do diagnóstico de arquivo visando a elaboração do vocabulário controlado? Objetivo apontar os elementos necessários para identificar a linguagem natural durante a realização do diagnóstico de arquivo para a elaboração do vocabulário controlado. Metodologia: A pesquisa caracteriza-se como exploratória e descritiva, utilizando a revisão bibliográfica como procedimento de pesquisa, visando proporcionar maior aprofundamento do objeto de estudo dessa pesquisa. Resultados: Obteve-se como principal resultado que, a inclusão da análise da linguagem natural da organização no processo de diagnóstico de arquivo é fundamental para a elaboração de vocabulário controlado, pois embasará os demais instrumentos arquivísticos. Aponta-se também os elementos que compõem um vocabulário controlado, como identificá-los no diagnóstico
\end{abstract}

a Doutoranda no Programa de Pós Graduação em Ciência da Informação da Universidade Estadual Paulista (PPGCI-UNESP). E-mail: izidio1985@yahoo.com.br

b Doutor em Ciência da Informação pela Universidade de São Paulo (USP). Docente do Programa de Pós-Graduação em Ciência da Informação da Universidade Estadual Palista (PPGClUNESP). E-mail: walter.moreira@unesp.br

c Doutoranda no Programa de Pós Graduação em Ciência da Informação da Universidade Estadual Paulista (PPGCI-UNESP). E-mail: luciana.davanzo@gmail.com

d Doutora em História Social pela Universidade de São Paulo (USP). Docente do Programa de Pós-Graduação em Ciência da Informação da Universidade Estadual Palista (PPGCI-UNESP).

E-mail: marcia.pazin@unesp.br 
de arquivo e os produtos gerados a partir da sua elaboração. Conclusões: Demonstrase a importância de fomentar e disseminar a necessidade de os arquivistas realizarem um diagnóstico de arquivo holístico incluindo a análise da linguagem natural, visando à construção de vocabulários controlados como foco na gestão de documentos.

Descritores: Gestão de documentos. Diagnóstico de Arquivo. Linguagem Natural. Linguagem Documentária. Vocabulário Controlado.

\section{INTRODUÇÃO}

As organizações têm buscado cada dia mais o tratamento adequado de suas informações. Quer sejam essas informações produzidas e recebidas diretamente pela organização, ou ainda oriundas do seu mercado consumidor, de seus concorrentes e de outras fontes de interesse. No entanto, não será possível recuperá-las e utilizá-las de modo eficaz sem a adoção de procedimentos de gestão de documentos (GD).

Devido ao próprio volume de informações registradas, requer-se do profissional da informação, na figura do arquivista, a realização de um trabalho minucioso, com criticidade, buscando assertividade na gestão de documentos / informações. A gestão de documentos envolve todas as etapas de gerenciamento da documentação e de arquivo para que, desse modo, as informações se tornem um ativo confiável e ágil.

Para implantar a GD, o arquivista realiza o diagnóstico de arquivo, uma etapa que fornece as bases para todos os demais processos da gestão de documentos. Um diagnóstico bem conduzido alicerça a construção de importantes instrumentos arquivísticos, tais como: o plano de classificação, a tabela de temporalidade documental, os instrumentos de pesquisa, os fluxogramas dentre outras ferramentas de gestão e acesso à documentação.

Para isso, o arquivista precisa conhecer o funcionamento e o fluxo das informações em todos os setores pelos quais se responsabiliza; precisa também conhecer o ramo de negócio em que atua; somente após essas análises em relação à ambiência da organização é que será possível propor as intervenções necessárias à organização, o que é possível por meio da gestão de documentos.

O diagnóstico de arquivo é uma atividade complexa que exige muita 
observação, aplicação de questionários, realização de entrevistas e de pesquisas na documentação, dentre outras atividades que propiciarão ao arquivista inteirar-se da organização, com intuito de gerir as informações e possibilitar sua futura recuperação.

Recuperar as informações é algo necessário a qualquer tipo de usuário (comum ou especializado), assim como para qualquer instituição (pública ou privada), por essa razão, o processo de representar a informação é uma atividade que faz a mediação entre os usuários e os sistemas de informação.

A Arquivologia faz uso de alguns instrumentos para que o processo de recuperação da informação aconteça de maneira mais consistente. Dentre esses instrumentos de pesquisa são considerados mais tradicionais na Arquivologia: guias, inventários e os catálogos. Um dos aspectos relevantes que deve ser considerado é a construção do elo entre o produtor, o acervo e seus usuários, como elemento fundamental a construção dos instrumentos de pesquisa.

Por essa razão, concorda-se com Brascher e Carlan (2010, p.35) quando as autoras inferem que "a qualidade obtida na recuperação da informação, depende, substancialmente, dos procedimentos e instrumentos utilizados para a organização da informação".

Quando não há clareza e objetividade no momento de se representar a informação, isso certamente contribuirá para que existam dificuldades na qualidade da relação que será estabelecida entre a tríade usuário-sistemainformação, a qual é marcada pela linguagem como elemento de intermediação.

Logo, desponta como necessária a adoção de instrumentos que reduzam ao máximo os ruídos comunicacionais causados pela ambiguidade e pela polissemia da linguagem natural que é usada pela organização. Nesse sentido, nesta pesquisa, serão abordadas as vantagens que os vocabulários controlados trazem para as organizações, contemplando sua utilização desde o início do processo de organização de arquivos, durante o diagnóstico.

$O$ instrumento de pesquisa atua como elemento comutador entre as linguagens do sistema, do usuário e do documento, isto é, proporciona a representação e a recuperação da informação pela promoção de uma linguagem 
comum entre os diversos "atores" envolvidos. Frequentemente os vocabulários controlados são elaborados posteriormente à organização do acervo, o que pode gerar retrabalhos.

Diante desse cenário, coloca-se como questão-problema desta pesquisa: quais elementos devem ser identificados durante a realização do diagnóstico de arquivo visando a elaboração do vocabulário controlado?

Para responder a esta questão, o objetivo norteador desta pesquisa consiste em apontar os elementos necessários para identificar a linguagem natural durante a realização do diagnóstico de arquivo para a elaboração do vocabulário controlado. Para tanto, foi realizada uma pesquisa exploratória e descritiva, por meio de uma revisão bibliográfica, com intuito de aproximar o pesquisador do assunto abordado, delimitando o tema da pesquisa. A partir de análise de autores mais citados nos assuntos centrais da pesquisa: "gestão de documentos", "diagnóstico de arquivo", "linguagem documentária" e "vocabulário controlado", foi possível aprimorar os fatos relevantes ao tema da pesquisa.

Espera-se com a construção desta pesquisa fomentar a discussão sobre a necessidade de identificar os elementos representativos da linguagem natural durante a realização de diagnóstico de arquivo para a elaboração de vocabulário controlado, uma vez que a padronização de termos é uma das atividades fundamentais e facilitadoras do acesso à informação.

\section{GESTÃO DE DOCUMENTOS}

As organizações necessitam cada dia mais gerenciar seus documentos e arquivos, pois mantê-los armazenados, de modo desordenado gera um alto custo financeiro. Além do custo, é preciso enfatizar que os documentos contribuem com as tomadas de decisões e a sua disponibilização evita que a organização seja penalizada devido à falta de comprovações relativas à auditoria, fiscalização, ação trabalhista e demais usos.

Por outro lado, o arquivo proporciona um reflexo das ações da organização; essas informações são registradas em documentos e devem ser administradas pelo arquivista, por meio da implantação da Gestão de 
documentos (GD). Ao abordar a GD, Rodrigues (2013, p.65) infere que a:

[...] gestão de documentos é um processo arquivístico que se caracteriza como um conjunto de procedimentos aplicados no controle dos documentos durante todo o seu ciclo de vida, incidindo sobre o momento da produção e acumulação na primeira e na segunda idade, ou seja, nos arquivos correntes e no intermediário.

Em consonância à garantia de acesso, a GD também propicia que o processo de eliminação de documentos aconteça de maneira adequada, a partir de estudos realizados em legislação que verse sobre a documentação que será destinada a eliminação, preservando tanto os documentos de guarda permanente, como aqueles que ainda não podem ser eliminados devidos aos seus prazos de guarda e devem estar disponíveis para consulta.

Valentim (2012, p.23) destaca as contribuições da GD:

A gestão documental em ambientes empresariais propicia melhoria considerável aos processos, fluxos, atividades e tarefas organizacionais. [...] proporciona maior eficiência e eficácia no que tange ao acesso, recuperação e disseminação de informações/documentos para todos os níveis hierárquicos da organização.

Além disso, a implantação da GD reflete-se nos arquivos permanentes no que tange à racionalização de documentos, pois somente chegarão a esses arquivos os documentos destinados à preservação. A economia de recursos financeiros também merece destaque; apesar de não ser foco da avaliação de documentos o descarte desenfreado de documentos, a existência de parâmetros para eliminação de documentos sem valor gera, sim, uma otimização de recursos, com a redução da massa documental acumulada.

Ao iniciar sua intervenção na produção de documentos, a GD otimiza também os processos e fluxos formais de informação da organização, uma vez que será possível identificar lacunas nos procedimentos que os regulamentam (LOUSADA; VALENTIM, 2010).

Para obter esses resultados é necessário planejamento e a realização de discussões com os responsáveis pela organização e seus colaboradores, para estabelecer medidas com a finalidade de garantir o controle de todos os documentos, visando à racionalização, à eficiência e à eficácia administrativas.

A Lei de Arquivos brasileira, $n . .8,159$, de 1991, contempla a GD e a define 
da seguinte forma:

Considera-se gestão de documentos o conjunto de procedimentos e operações técnicas referentes à sua produção, tramitação, uso, avaliação e arquivamento em fase corrente e intermediária, visando a sua eliminação ou recolhimento para guarda permanente (BRASIL, 1991, Art. 3ํ).

Essa Lei foi um marco importante para a Arquivologia, pois a elaboração de uma Lei sempre propicia discussões entre os profissionais, fomentando o debate e dando visibilidade à área de atuação. A definição apresentada na lei também se tornou um marco técnico relevante, tendo sido adotada pelo Dicionário Brasileiro de Terminologia Arquivística (ARQUIVO NACIONAL, 2005).

A GD assume papel de destaque para as organizações porque, a partir dela, é possível melhorar de modo significativo a maneira pela qual as atividades são desempenhadas no que se refere à produção, uso e destinação dos documentos. No caso das organizações privadas, estas devem considerar também os aparatos jurídicos que cercam as séries documentais, tais como: documentos de recursos humanos, contabilidade, financeiro, entre outros.

Para propiciar acesso rápido às informações, a GD envolve todo o ciclo de vida dos documentos e, com a elaboração do Plano de Classificação, Tabela de Temporalidade Documental, instrumentos de controle, de pesquisa, dentre outros, cria meios de proporcionar à organização vantagem na competição do mercado em que se insere, no que se refere ao fornecimento de informações ágeis e precisas para ampliação da qualidade da tomada de decisão.

A importância atribuída ao domínio e administração das informações por parte das organizações é defendida por Ponjuán Dante (2008, p. 27)

La información comenzó a dominar la economía. Se hizo énfasis en la organización de la producción corporativa para tomar ventajas en los cambios en la sociedad y en la tecnología de información. Las alzas en la producción y la distribución, el crecimiento de las grandes organizaciones, la aparición de nuevas industrias de información y la profesionalización de muchas formas del trabajo informacional se consideran ejemplos a tener en cuenta como indicadores de esta situación.

Considerando que a gestão de documentos faz parte do processo de gestão da informação, antes de se elaborar os instrumentos, é necessário, primeiramente, que se conheça de modo amplo e aprofundado a organização, a 
partir da coleta de informações. Esse processo ocorre mediante a elaboração diagnóstico de arquivo. Desse modo, espera-se que o profissional tenha subsídios suficientes para conhecer a estrutura organizacional de onde está inserido e implantar uma GD capaz de atender seus diversos usuários.

\subsection{Diagnóstico de Arquivo}

As metodologias de diagnóstico de arquivo precisam contemplar de maneira ampla as necessidades do arquivista, no que tange as bases para elaboração e aplicação do plano de classificação, tabela de temporalidade, instrumentos de pesquisa, ordenação física, entre outros procedimentos arquivísticos. De acordo com Aranda, Rodriguez e Mugica (2012, p. 578):

[...] el diagnóstico se realiza para diseñar y desarrollar un programa de gestión documental, que obedece a un plan de acción con líneas concretas, que facilite su implementación de manera efectiva, contemple la identificación de problemas, oportunidades y objetivos, análisis y determinación de los requerimientos de información, mantenimiento, evaluación y documentación del programa, planes de mejoramiento y planes de contingencia.

Para isso, é preciso conhecer o trâmite documental e informacional da organização, iniciando com o mapeamento das informações, sendo essa uma atividade preliminar que embasará a coleta de informações mais aprofundada. que pode ocorrer por meio da elaboração de fluxogramas dos processos.

Em seguida o arquivista realiza o diagnóstico de arquivos propriamente dito, que Camargo e Bellotto (2010, p.37) definem como:

Análise das informações básicas (quantidade, localização, estado físico, condições de armazenamento, grau de crescimento, frequência de consulta e outras) sobre arquivos, a fim de implantar sistemas e estabelecer programas de transferência, recolhimento, microfilmagem, conservação e demais atividades.

Além da análise das informações básicas propostas por Camargo e Bellotto (2010), o arquivista precisa identificar a documentação produzida e os elementos que proporcionam essa produção, ou seja, elementos informacionais e documentais.

Lopes (2009, p.155) define diagnóstico como "a operação de construir a 
imagem de uma ou mais organizações". Para tanto, torna-se substancial uma investigação aprofundada sobre a organização e não somente em torno do arquivo e do conjunto de documentos. $O$ autor indica que a solução das dificuldades "[...] está numa Arquivística e em profissionais que possam se impor por suas autoridades intelectuais, derivadas da pesquisa e da experimentação" (LOPES, 2009, p.159).

Práticas comuns, termo contemplado por Lopes (2009), são históricas na área, por tratar-se de uma ciência recente; porém é preciso modificar esse cenário e, isso somente será possível com ampliações de pesquisa e com a realização do fluxo teoria - prática - teoria.

Para tanto, realizar

Um diagnóstico de arquivo elaborado com criticidade torna possível propor soluções não só para os problemas físicos do arquivo, problemas com massas documentais acumuladas, como também para os problemas informacionais. A solução desses problemas proporcionará à organização 0 melhor desenvolvimento de suas atividades cotidianas e, também, de atividades de nível estratégico (ALMEIDA; VITORIANO, 2018, p. 84).

Considerando a necessidade de uma visão sistêmica e abrangente do arquivo e de seus documentos, dentre as diversas opções de metodologias de diagnóstico de arquivos, optou-se por investigar uma proposta voltada à análise de informações sobre a produção documental, como a apresentada na obra "Arquivos de empresas: tipologia documental" de Pazin (2005). A escolha justifica-se por ser essa uma proposta de diagnóstico de arquivo voltada para a produção documental, por abordar elementos além das estruturas físicas do arquivo e por ter foco no estudo dos tipos documentais, fundamental para a constituição de séries documentais e padronização de termos.

Entende-se, com isso, que a fase de diagnóstico de arquivos deve contemplar tanto as questões físicas, quanto o levantamento inicial da composição do acervo documental, numa etapa anterior à de Identificação Arquivística, como definido por Rodrigues (2013), de modo a contribuir para o planejamento das ações necessárias ao aprofundamento da análise da tipologia documental da organização. 
Para esta análise, foi utilizado o capítulo intitulado "II - Diagnóstico da produção documental", no qual a autora aborda o diagnóstico da produção documental como a primeira etapa da organização de documentos. A autora argumenta que o diagnóstico "deve ser iniciado com o levantamento de informações sobre a entidade geradora do arquivo" (PAZIN, 2005, p. 09). Logo, estudar os documentos oficiais da organização torna-se substancial e, para tal destacam-se os seguintes documentos: contrato social, atas de reunião, estatutos, regimentos, organogramas, entre outros.

Outro fator contributivo para o arquivista inteirar-se da organização é conhecer a trajetória de vida dos fundadores da organização, bem como sua direção e gestores, com base na expectativa de que esses sujeitos possuam conhecimentos que abarcam desde a cultura da organização, sua evolução e colaboradores. "Para compreender o arquivo, é necessário compreender quem o produziu" (PAZIN, 2005, p. 9).

É importante levantar informações acerca das funções da organização, de modo a relacioná-las com os documentos produzidos. Essa relação é estabelecida quando são realizadas entrevistas com os colaboradores, mapeamento dos depósitos de documentos e estudo de quadro de funções e atividades.

De acordo com Pazin (2005, p. 10) "as entrevistas produzem um material riquíssimo para compreender 0 arquivo. Devem ser realizadas com os responsáveis pelas áreas [...]". As entrevistas devem englobar identificação do setor, assim como suas funções, atividades desenvolvidas, documentos produzidos/ recebidos e informações sobre o arquivamento desses documentos.

Levantar as características físicas do arquivo também é fundamental para aplicar uma intervenção, isso deve ocorrer a partir do mapeamento de depósitos de documentos: "[...] dados de localização, volume documental [...] e dados dos conjuntos localizados (identificação de nomes dos setores ou tipos documentais visíveis nas embalagens)" (PAZIN, 2005, p.10).

Após esse levantamento, propõe-se uma análise mais crítica, voltada às características intrínsecas do documento, ou seja, as informações registradas no 
documento. Nessa fase, Pazin (2005, p. 10) sugere um roteiro para coletar informações mais específicas acerca do documento, tais como: "1. Quem produziu o documento? (Estrutura); 2. Por que o documento é produzido? (Função) e 3. Qual o caminho percorrido pelo documento ao cumprir sua função administrativa? (Trâmite)" (PAZIN, 2005, p. 10).

Ao final dessa primeira etapa de trabalho, o arquivista terá elementos iniciais suficientes que vão colaborar em relação à análise dos tipos documentais durante o processo de Identificação Arquivística. Identificar a tipologia documental da organização é etapa essencial para o trabalho de padronização dos termos, pois, além de identificar os documentos produzidos, também contribuem para o estudo das funções e atividades da organização e para a padronização da terminologia utilizada na sua denominação.

Compreender a linguagem utilizada na organização para nomear e localizar os documentos auxiliará o arquivista neste momento crucial de atribuir a nomenclatura para as séries documentais. Após os termos e séries documentais identificados e definidos é possível elaborar o vocabulário controlado e divulgá-lo para a organização, para facilitar e proporcionar o acesso do usuário à informação.

\section{VOCABULÁRIO CONTROLADO}

A Arquivologia possui uma gama de instrumentos que propicia o gerenciamento de informações (instrumentos de controle e de pesquisa - guias, inventários e catálogos, plano de classificação, dentre outros), independentemente do suporte no qual essas informações estejam registradas. Esses instrumentos, já consolidados pela área, possuem o objetivo de garantir a recuperação da informação e proporcionar seu acesso em tempo hábil, para diversos usos: nas tomadas de decisões, nas apresentações de informações em fiscalizações, para apoio às ações trabalhistas, dentre outras necessidades legais e administrativas, que estão diretamente ligadas ao cotidiano das organizações, sejam públicas ou privadas.

Mesmo que a recuperação dos documentos ou da informação contida 
neles tenha sido considerada um elemento importante para a gestão de documentos, as teorias arquivísticas clássicas não consideravam a padronização terminológica como uma etapa fundamental na construção dos instrumentos arquivísticos.

Somente nos Anos 1990, a Arquivologia passa a se preocupar com a questão da normalização a partir do desenvolvimento das normas de descrição, o que para a área foi um grande avanço, principalmente devido às tecnologias digitais, que influenciaram de maneira decisiva o modo de produção, organização, recuperação e armazenamento da informação e, por consequência, também modificaram os processos de difusão e compartilhamento da informação.

Esses avanços seguiram, fato marcado pela tradução da Norma Internacional de Descrição Arquivística (ISAD (G), (2000), que posteriormente impulsionou a elaboração da Norma Brasileira de Descrição Arquivística (NOBRADE, 2006)

Neste contexto, surgiram os primeiros trabalhos de aplicação de vocabulários controlados para arquivos, sistematizados por Smit e Kosbashi (2003) em um manual onde a partir de experiências internacionais, as autoras demonstravam que os vocabulários controlados constituem instrumentos de controle terminológico que podem melhorar significativamente o índice de recuperação da informação dos documentos de arquivo.

O Arquivo Nacional da Austrália, define os vocabulários controlados como

Uma ferramenta de classificação para ajudar as organizações a gerenciar seus registros e outras informações comerciais. É uma lista controlada de termos unidos por relações semânticas, hierárquicas, associativa ou de equivalência. Essa ferramenta atua como um guia para atribuir os termos de classificação aos registros individuais (Arquivo Nacional da Austrália, 2010, p. 07).

Investigar, compreender, padronizar e construir um vocabulário controlado com termos adequados a cada instituição, sem dúvida, facilitará a comunicação entre usuários, incluindo-se nessa categoria arquivistas, pesquisadores e, sistema. Os vocabulários controlados também diminuem os atritos que possam ocorrer devido à carência de orientações sobre a maneira 
como as informações foram armazenadas no sistema.

O tesauro, pelo maior detalhamento nas relações conceituais, é considerado um dos modelos mais avançados de vocabulário controlado. A norma ISO 25964-1 (ISO, 2011), que Ihe dispensa bastante atenção, o define do seguinte modo:

[...] vocabulário controlado e estruturado em que os conceitos são representados por termos, organizados de modo que as relações entre conceitos sejam explicitadas e os termos preferidos sejam acompanhados por termos de entrada para sinônimos ou quase-sinônimos.

Nesse contexto, os vocabulários controlados atuam para melhorar a eficácia em relação a recuperação da informação, mas também abarcam questões que melhoram as formas de organização e representação da informação.

Muitas vezes, pode parecer que outros instrumentos arquivísticos contemplem a padronização de termos, mas, o controle terminológico não é preocupação do plano de classificação (instrumento consolidado pela área) e, por essa razão, acredita-se que o uso dos vocabulários controlados pela Arquivologia pode suprir essa lacuna, uma vez que os vocabulários controlados

Possuem características que se aproximam do paradigma do usuário (sistema focado no usuário, isto é, a preocupação com as linguagens), ao comportar: relacionamentos entre descritores (principalmente relações de equivalência); base temática; o controle de vocabulário, ao contrário dos planos de gestão (planos ou quadros de classificação) que são orientados (focados) no sistema documental (nomeação estrutural ou funcional de unidades documentais) (AGUIAR; TALÁMO, 2012, p. 135).

O Dicionário Brasileiro de Terminologia Arquivística (ARQUIVO NACIONAL, 2005, p.132) menciona que o plano de classificação objetiva produzir um: "Esquema de distribuição de documentos em classes, de acordo com métodos de arquivamento específicos, elaborado a partir do estudo das estruturas e funções de uma instituição e da análise do arquivo por ela produzido".

Com isso, ficam evidentes a funcionalidade e os objetivos do plano de classificação: nortear a organização e 0 arquivamento dos documentos. 
Defende-se que, ao elaborar o plano de classificação, as séries documentais precisam estar padronizadas e, essa padronização pode ser subsidiada de acordo com um vocabulário controlado, construído após o diagnóstico de arquivo, durante a fase de identificação, que contemple a análise da linguagem natural da organização e a padronização dos diferentes termos utilizados em uma estrutura unificada. Como apontam Smit e Kobashi:

A organização física dos documentos, embora deva continuar sendo feita de forma rigorosa, não é, de modo geral, suficiente para garantir a recuperação da informação em diferentes situações. $O$ caos instala-se com relativa facilidade, e raramente o vilão é corretamente identificado: o controle de vocabulário ou o seu descontrole (SMIT; KOBASHI, 2003, p. 14).

O uso dos vocabulários controlados, combinados aos planos de classificação, possibilita que a indexação e a recuperação da informação sejam realizadas de maneira mais consistente, principalmente para aqueles usuários que não possuem muita familiaridade com o sistema, ou que não sabem exatamente como conduzir a sua pesquisa. $O$ vocabulário controlado será 0 condutor desse processo que envolve o usuário e o sistema, isto é, "muitas vezes, usuários finais não são especialistas e, portanto, precisam ser guiados porque é possível que não conheçam o termo correto" (HARPRING, 2016, p.17).

Alencar (2017) apresenta a importância do uso do vocabulário controlado para a Arquivologia ao refletir que o uso desse instrumento contribui em relação ao acesso, pois uma linguagem padronizada colabora para que o usuário tenha um caminho flexível e amplo até chegar à informação desejada. Assim, no ambiente arquivístico, a representação da informação através do uso do vocabulário controlado permite representar a informação considerando o contexto de produção dos documentos.

Percebe-se, então, que os instrumentos que colaboram com a padronização da informação agregam-se aos processos de gestão de documentos / informações, uma vez que abarcam a estimulação de "cuidado em relação ao controle de vocabulário ao se nomear, por exemplo, as funções, atividades e séries documentais no contexto dos instrumentos de gestão documental [...]" (SMIT; KOBASHI, 2003). 
Considerando-se a literatura e as práticas arquivísticas, existe muito ainda a ser investigado sobre o uso do vocabulário controlado pelos arquivistas. Porém, defende-se que o início da construção do vocabulário controlado a partir da realização do diagnóstico de arquivo agrega importante valor ao processo de organização, representação e recuperação da informação, uma vez que ele comporta o levantamento básico de informações que embasará outras etapas dos trabalhos dos arquivistas, como a descrição dos documentos.

Destaca-se que os vocabulários controlados permitem melhorias em relação aos ruídos de comunicação existentes entre usuários e sistemas de informação. Tais ruídos impactam na recuperação da informação, sobre esse assunto, Moreira et al. $(2015$, p.3) observam que:

Considerando-se a perspectiva mediadora dos arquivos, acredita-se que, sem o recurso da padronização terminológica na representação documentária, prejudica-se o fluxo de comunicação. Na ausência de controle terminológico por meio de linguagem documentária, isso é, sem a adoção de procedimentos de desambiguação da linguagem natural, realizase um uso pobre da linguagem em si, enquanto elemento capaz de sintetizar e sistematizar conceitos.

Partindo desse pressuposto, no âmbito das linguagens documentárias (LD), o vocabulário controlado, além de contribuir com as práticas arquivísticas, também contribui com a interação entre arquivista-arquivo-usuário, pois, "as LDs, como instrumentos da representação documentária, são construídas para possibilitar a comunicação entre os conteúdos dos documentos e os usuários de um sistema de informação", conforme salientam (CAVATI SOBRINHO; FUJITA, 2015, p.03).

Dessa maneira, compreende-se que as LDs contribuem para a disseminação da informação, servindo como pontes entre os usuários e os sistemas.

Uma das principais funções da LD é funcionar como uma espécie de código comutador entre a linguagem natural, portanto mais livre e polissêmica, mas também substancialmente mais rica, e o vocabulário controlado adotado pelo sistema. Uma LD é, no limite, sempre uma redução em relação às diversas funções que a linguagem natural pode assumir. Nesse caso específico, a 
linguagem documentária desempenha principalmente a função descritiva (informativa, referencial) e a função prescritiva.

Desse modo, a utilização de um vocabulário controlado coloca-se como condição necessária para a efetividade das ações de representação e de recuperação da informação. É importante lembrar que nas ações de representação estão incluídas tanto aquelas que são realizadas pelo usuáriopesquisador quanto às que realizam os arquivistas.

É de conhecimento relativamente comum que um documento representado a partir de várias nomenclaturas pode apresentar conflitos ao permitir que a "busca seja realizada de forma dissociada do registro, ou seja, a busca é feita de forma diferenciada da entrada de dados no sistema". (FREITAS; SIMIONATO; ALBUQUERQUE, 2015, p. 1). Por isso, o vocabulário controlado é necessário, uma vez que é

Utilizado para melhorar a eficácia dos sistemas de armazenamento e recuperação da informação, das pesquisas na Web e de outros ambientes que buscam identificar e localizar os conteúdos desejados por meio de descrições de conteúdo padronizadas. Esse tipo de instrumento tem como principal objetivo a consistência na descrição do conteúdo para facilitar a recuperação (ANSI/NISO Z39.19 - 2005 (2010).

No contexto da Gestão de Documentos, a construção de um vocabulário controlado associado aos instrumentos de gestão, amplia o acesso aos documentos, pois "vocabulários controlados são conjuntos organizados de valores de terminologia controlada" (HARPRING, 2016, p. 39). Para a autora:

O vocabulário controlado é uma ferramenta de informação que contém palavras e frases padronizadas usadas para se referir a ideias, características físicas, pessoas, lugares, eventos, assuntos e muitos outros conceitos. Vocabulários controlados permitem a categorização, a indexação e a recuperação de informações (HARPRING, 2016, p. 24).

Logo, o vocabulário controlado é um instrumento essencial à GD, sendo necessário iniciar sua construção o quanto antes, partindo do levantamento da linguagem natural desde a elaboração do diagnóstico de arquivo, pois sua aplicação norteará os demais instrumentos arquivísticos, propiciando a representação e a recuperação da informação. 


\subsection{IDENTIFICAÇÃo de Elementos BÁSICOS Ao VocabuláRIo Controlado}

A elaboração do vocabulário controlado perpassa momentos cruciais da organização, destacando-se justamente a relação entre disseminação e acesso à informação. Por meio do controle de vocabulário obtém-se maior precisão para recuperar a informação desejada através do estabelecimento de padrões, aplicados para representar a informação.

Por ter reflexos tão diretos no funcionamento dos arquivos e uso das informações, defende-se neste artigo que a elaboração do diagnóstico de arquivo contemple elementos que subsidiem a construção do vocabulário controlado.

O primeiro passo para essa atividade é identificar elementos utilizados em normas internacionais e demais referências bibliográficas. Durante a realização do diagnóstico de arquivo será possível identificar quais desses elementos são contributivos ao acesso e à recuperação da informação. É preciso observar, adicionalmente, a linguagem natural utilizada na organização. Compreende-se por linguagem natural o conjunto de palavras e/ou expressões utilizadas livremente, sem controle de vocabulário, portanto, para os fins de produção dos documentos.

Dentre os manuais e normas que subsidiam podem ser consultados como base de apoio para o desenvolvimento dos vocabulários controlados, destacase a publicação "Como elaborar vocabulário controlado para aplicação em arquivos" (SMIT; KOBASHI, 2003), e a ISO 25964 (2011), sendo está a publicação mais recente sobre a temática proposta nessa pesquisa.

Destaca-se também a atuação do Arquivo Nacional da Austrália, que elaborou um passo-a-passo para a elaboração de um tesauro funcional. De modo simplificado, um tesauro funcional, é um tipo de tesauro/ vocabulário controlado aplicado à padronização da descrição das funções previstas no plano de classificação. A esse respeito, pode-se consultar o trabalho de Alencar (2019), o qual apresenta um estudo teórico-metodológico orientado para a construção de tesauros funcionais como fundamentos da Arquivística PósCustodial. 
Certamente os trabalhos de Smit e Kobashi (2003), do Arquivo Nacional da Austrália (2003) e de Alencar (2019) são importantes contribuições para a Arquivologia, por indicarem como esse instrumento pode ser desenvolvido e utilizado de maneira específica pela área.

É necessário ressaltar que a necessidade do uso dos vocabulários controlados é observada na Norma Internacional de registro de autoridade arquivística para entidades coletivas, pessoas e famílias (ISAAR CPF). É possível encontrar a indicação do vocabulário controlado na área de relacionamentos, destinada a "descrever os relacionamentos com outras entidades coletivas, pessoas e famílias que podem ser descritas em outros registros de autoridade" (ISAAR (CPF), 2004, p.26).

Não obstante, é preciso observar que embora a ISAAR (CPF) mencione a necessidade do uso do vocabulário controlado, não há explicação de como esse instrumento deve ser desenvolvido e utilizado pela Arquivologia, por essa razão, é necessário recorrer a outras publicações que abarquem a temática para aproximar esse instrumento da realidade da Arquivologia.

Os trabalhos mencionados informam quais são os elementos que devem ser contemplados no momento do desenvolvimento dos vocabulários controlados, logo ao realizar o diagnóstico de arquivo, o arquivista poderá atentar-se aos critérios essenciais para sua elaboração. No recorte desta pesquisa objetivou-se analisar a pertinência dos elementos a serem identificados durante o diagnóstico documental, a partir de sua ocorrência em três textos que contemplam os vocabulários controlados: como elaborar vocabulário controlado para aplicação em arquivos, a norma ISAAR (CPF) e a ISO 25964-1.

Tais publicações oferecem subsídios para a fundamentação de vocabulários controlados que considerem as funções e atividades que são desenvolvidos pelos arquivos. Para este objetivo, a publicação de SMIT; KOBASHI (2003) se tornou um marco relevante para a área, por destacar quais são os elementos básicos que devem estar presentes no vocabulário controlado. Porém, não se pode negar a necessidade do uso da ISO 25964-1, que possui maior abrangência que o manual de SMIT; KOBASHI (2003). Nesse sentido, ao 
Maria Fabiana Izidio de Almeida, Walter Moreira, Luciana Davanzo, Márcia de Carvalho Pazin Vitoriano

Identificação de elementos para construção do vocabulário controlado: contribuições do diagnóstico de arquivo

considerar que a Arquivologia começa a pensar as questões de padronização da informação a partir das normas de descrição, essa pesquisa contempla a ISAAR (CPF), uma vez que a criação de vocabulários controlados é indicada nessa norma, conforme relatos anteriores.

O Quadro 1, a seguir, demonstra os elementos essenciais para a elaboração de vocabulários controlados, a partir da análise dos elementos identificados em cada uma das obras citadas anteriormente.

\section{Quadro 1 - Elementos básicos necessários para a elaboração de vocabulário controlado}

\begin{tabular}{|c|c|c|c|}
\hline $\begin{array}{l}\text { Composição dos elementos } \\
\text { de um vocabulário } \\
\text { controlado }\end{array}$ & $\begin{array}{l}\text { ISAAR } \\
\text { (CPF) }\end{array}$ & $\begin{array}{c}\text { Projeto } \\
\text { Como } \\
\text { Fazer } \\
\end{array}$ & $\begin{array}{c}\text { ISO } \\
25964\end{array}$ \\
\hline 1. Normalização gramatical & Presente & Presente & Ausente \\
\hline 2. Opções de grafia & Presente & Presente & Presente \\
\hline $\begin{array}{l}\text { 3. Alterações nos nomes de } \\
\text { pessoas ou topônimos }\end{array}$ & Presente & Presente & - \\
\hline $\begin{array}{l}\text { 4. Controle de sinonímia, } \\
\text { homonímia e quase- } \\
\text { sinonímia }\end{array}$ & Presente & Presente & Presente \\
\hline $\begin{array}{l}\text { 5. Adoção de termos } \\
\text { compostos }\end{array}$ & Presente & Presente & - \\
\hline $\begin{array}{l}\text { 6. Introdução de notas de } \\
\text { escopo e notas de uso }\end{array}$ & Presente & Presente & Presente \\
\hline $\begin{array}{l}\text { 7. Tipologia de vocabulários } \\
\text { controlados }\end{array}$ & Ausente & Presente & Ausente \\
\hline $\begin{array}{l}\text { 8. A construção de um plano } \\
\text { de classificação }\end{array}$ & Ausente & Presente & Ausente \\
\hline $\begin{array}{l}\text { 9. A construção de um } \\
\text { tesauro funcional }\end{array}$ & Ausente & Presente & Presente \\
\hline $\begin{array}{l}\text { 10. A elaboração de listas } \\
\text { alfabéticas } \\
\text { complementares à } \\
\text { ordenação dos termos }\end{array}$ & Ausente & Presente & Presente \\
\hline
\end{tabular}

Fonte: Davanzo (2016, p. 93) 
Ao considerar a riqueza da língua e da cultura de cada país, observa-se que os itens denominados de "elementos essenciais" são contributivos para o desenvolvimento do vocabulário controlado, pois objetivam auxiliar o usuário e/ou pesquisador a ter melhores resultados a partir de estratégias de busca préestabelecidas que irão indicar as formas adequadas para atender as demandas informacionais recebidas pelos arquivos.

Os elementos de 1 a 6 estão relacionados ao tratamento da linguagem natural, visando contribuir com melhorias em relação à padronização e ao controle terminológico dos termos. O elemento 7 abarca questões acerca dos tipos de vocabulários controlados (tesauro). $O$ elemento 8 se refere a um dos instrumentos de gestão de documentos consolidados pela Arquivologia, que demonstram todas as informações subjacentes à instituição, relativas às funções atividades e tipos documentais existentes. $O$ item 9 relaciona-se ao desenvolvimento do instrumento de padronização e controle terminológico, no caso, as autoras citam o tesauro funcional, uma vez que tal instrumento é desenvolvido a partir da análise das funções e atividades desenvolvidas pelos arquivos, identificadas tanto no plano de classificação, quanto em outros instrumentos de gestão, o que contribui para não ferir os princípios da área, tais como organicidade, unicidade, indivisibilidade etc. E, por fim o item 10 demonstra a necessidade de listas e índices remissivos para auxiliar os usuários em relação aos itens dispostos no vocabulário controlado.

Conhecer os elementos pertinentes à construção do vocabulário controlado torna-se substancial. Para tanto, destaca-se que a construção dessa ferramenta perpassa dois momentos distintos, isto é, antes do momento da construção do vocabulário controlado "onde são levadas em consideração a política da instituição como um todo (sua missão e objetivos) e as atividades/funções que estão envolvidas na documentação a ser organizada (linguagem de especialidade)", conforme salientam Smit e Kobashi (2003, p. 18), há um momento de levantamento de informações que subsidiarão a efetiva construção do vocabulário controlado. Idealmente este processo deve ter início durante o primeiro contato com o acervo, durante o diagnóstico do arquivo. 
A observação dos elementos apresentados no Quadro 1 durante a elaboração do diagnóstico de arquivo favorecerá a construção de um vocabulário controlado útil e efetivo, que atenderá ao processo de acesso, representação, recuperação e uso da informação. Nota-se que os elementos apresentados no Quadro 1 perpassam diferentes momentos e buscam a identificação de muitas informações a respeito da documentação e linguagem utilizada.

Percebe-se que os itens listados compõem elemento de controle vocabular preconizados pelas linguagens documentárias, associados ao elemento técnico arquivístico, que é o plano de classificação.

\section{METODOLOGIA}

Esta pesquisa objetivou apontar os elementos necessários para identificar a linguagem natural durante a realização do diagnóstico de arquivo para a elaboração do vocabulário controlado. Para tanto, utilizou-se uma pesquisa qualitativa, do tipo descritiva-exploratória. Para Diehl e Tatim (2004, p.54) a pesquisa descritiva "[...] tem como objetivo primordial a descrição das características de determinada população, fenômeno ou, então o estabelecimento de relações entre variáveis". No que se refere a pesquisa exploratória, essas "[...] são desenvolvidas com o objetivo de proporcionar visão geral, de tipo aproximativo, acerca de determinado fato" (GIL, 1994, p. 45).

Como método utilizou-se a revisão bibliográfica com intuito de relacionar as temáticas linguagem natural, linguagem documentária, vocabulário controlado e diagnóstico de arquivo.

As referências que compõem está pesquisa foram localizadas em bases de dados da Ciência da Informação, tais como: Base de Dados Referenciais de Artigos de Periódicos em Ciência da Informação (BRAPCI), Scielo e Web of Science, Portal de Periódicos da CAPES, selecionando autores referenciados na Ciência da Informação e demais obras pertinentes aos assuntos abordados.

Em um segundo momento, foram identificadas obras que referenciavam itens essenciais para a elaboração de um vocabulário controlado, conforme demonstrado no Quadro 1 "Elementos básicos necessários para a elaboração 
de vocabulário controlado". Com o levantamento realizado sobre a temática de diagnóstico de arquivo foi possível reconhecer a relevância da linguagem natural utilizada na organização para uma intervenção e implantação da gestão de documentos eficiente.

A partir da análise dos elementos coletados na pesquisa bibliográfica, foi elaborado o Quadro 2 "Como identificar os elementos para construção de vocabulário controlado", que demonstra os elementos que compõem um vocabulário controlado, como identificá-los no diagnóstico de arquivo e os produtos gerados a partir da sua elaboração.

\section{APRESENTAÇÃO DE RESULTADOS}

A partir das pesquisas bibliográficas e referencial teórico construído nesta pesquisa foi possível apontar quais são os elementos essenciais que devem ser identificados no diagnóstico de arquivo, em momento anterior ao início da organização, que serão contributivos para a elaboração do vocabulário controlado.

Partindo da análise dos elementos expostos no Quadro 1 foi elaborada uma síntese sobre como identificar os elementos para construção de vocabulário controlado, que segue apresentado no Quadro 2 - "Como identificar os elementos para construção de vocabulário controlado", apontando em qual momento do diagnóstico de arquivo é possível identificar os elementos que devem compor o vocabulário controlado, tendo em vista a padronização dos nomes das séries documentais. Em seguida, apresenta-se também o produto gerado a partir dessa análise.

\section{Quadro 2 - Como identificar os elementos para construção de vocabulário controlado}

\begin{tabular}{|l|l|lll|}
\hline \multicolumn{1}{|c|}{$\begin{array}{c}\text { Composição dos } \\
\text { elementos de um } \\
\text { vocabulário controlado }\end{array}$} & \multicolumn{1}{|c|}{ Como diagnosticar } & \multicolumn{3}{|c|}{ Produto } \\
\hline $\begin{array}{l}\text { - Normalização gramatical } \\
\text { - Opções de grafia }\end{array}$ & $\begin{array}{l}\text { - Levantamento dos tipos } \\
\text { documentais }\end{array}$ & $\begin{array}{l}\text { A elaboração de listas } \\
\text { - Controle de sinonímia } \\
\text {-Controle de homonímia }\end{array}$ & $\begin{array}{l}\text { - Verificação e análise de } \\
\text { instrumentos de pesquisa }\end{array}$ & $\begin{array}{l}\text { - Introdução de notas de de } \\
\text { escopo e notas de uso }\end{array}$ \\
\hline
\end{tabular}




\begin{tabular}{|ll|l|l|}
\hline - Controle de quase- & - Controles diversos & - Lista alfabética \\
sinonímia & & - Entrevistas & - Notas de escopo \\
& & - Análise de protocolos de & - Notas de Usos \\
& empréstimo e devolução & - Relação de remissiva \\
& & - Vocabulário Controlado \\
\hline
\end{tabular}

Fonte: Elaborado pelos autores (2019)

A normalização gramatical contempla a padronização dos termos tendo em vista o seu gênero (feminino/ masculino) e o número (plural/singular). Um dos benefícios da implantação da normalização gramatical é evitar a duplicidade dos nomes das séries documentais. Assim como as opções de grafia, é preciso adotar uma maneira única de utilização, lembrando que as listas remissivas devem ser construídas e, é justamente durante o diagnóstico de arquivo que o levantamento acontece.

Ainda sobre a opção de grafia, entende-se que este seja um dos grandes pontos de atenção, principalmente ao considerar que o processo de busca de uma informação pode acontecer de diversas maneiras. Cada usuário busca uma informação a partir de suas próprias experiências e, por isso, na elaboração de um vocabulário controlado deve-se tentar ao máximo não suprimir nenhuma informação, ao contrário, deve-se usar remissivas para que as solicitações de informação sejam atendidas de maneira eficaz.

O controle da sinonímia, homonímia e quase sinonímia, este item também merece destaque devido ao cuidado em relação ao uso de expressões que serão usadas para representar uma informação / documento (SMIT; KOBASHI, 2003). Ao lado do controle da grafia, a definição de termos sinônimos e a identificação do termo a ser utilizado de modo preferencial, é um dos elementos mais representativos e de maior dificuldade para implantação dos vocabulários controlados em arquivos, por se tratar de um elemento relativo ao uso cultural da terminologia no ambiente da organização.

A etapa de levantamento das funções, atividades e dos tipos documentais produzidos fornece informação sobre a nomenclatura utilizada, a partir da linguagem natural. Neste momento, são localizados muitos casos de sinonímia ou quase sinonímia que só podem ser adequadamente normalizados se a categorização técnica (arquivística) é bem estabelecida, tanto durante $o$ 
levantamento dos tipos documentais, quanto durante a etapa de entrevistas com os produtores.

Em se tratando de termos técnicos de áreas especializadas, por exemplo, a contábil-fiscal, a diferença entre documentos pode ser uma questão de análise do conteúdo e do contexto de produção. Fisicamente, uma nota fiscal de aquisição de materiais (documento fiscal que oficializa a aquisição de materiais e bens pela empresa) só é diferente de uma nota fiscal de venda (documento fiscal que oficializa operação comercial de venda) porque o nome do emissor é diferente. No próprio documento, em sua produção, ambos são identificados como "nota fiscal de venda". A questão que se coloca é: venda de quem? Quem vendeu e quem comprou? A resposta definirá o tipo documental e a posição da nota no plano de classificação. Esse processo também está intimamente ligado à criação de notas de escopo.

Vale ressaltar que as normas e manuais de desenvolvimento de vocabulários controlados, já citados anteriormente, apresentam diversos dispositivos para a redução e eliminação de ambiguidade, dentre os quais o mais conhecido é o uso de um qualificador entre parênteses. No exemplo apresentado, uma solução possível seria a utilização da terminologia "nota fiscal de venda (aquisição de materiais)" e nota fiscal de venda (venda de produtos)".

As notas de escopo "[...] têm por finalidade explicitar a amplitude ou o entendimento atribuído ao conceito" (SMIT; KOBASHI, 2003, p. 31-32). Podem ser usadas como estratégias para facilitar e gerar maior confiabilidade e consistência em relação à recuperação da informação. E, sobre as notas de uso, elas "voltam-se para uma explicitação de recomendações práticas de uso do termo" (SMIT; KOBASHI, 2003). No caso dos planos de classificação, elas são essenciais para dirimir dúvidas e identificar categorias técnicas presentes nos tipos documentais. Ao mesmo tempo, as notas de uso incorporam elementos históricos particularmente importantes nos arquivos para garantir 0 acompanhamento das mudanças terminológicas ao longo do tempo, principalmente no que se refere à nomenclatura utilizada para definir setores, departamentos e, até mesmo, espécies e tipos documentais, em momentos 
anteriores à organização do arquivo. O diagnóstico é um momento muito importante para o levantamento e registro desses elementos para posterior categorização nos instrumentos de gestão.

A elaboração de listas alfabéticas complementares à ordenação sistemática dos termos está relacionada às maneiras pelas quais os termos foram adotados pelo sistema, sendo que essas listas são estruturadas de acordo com a natureza da opção de adoção e uso dos termos: se adotados ou não adotados.

os termos adotados pelo sistema em ordem alfabética, ou seja, eles são acessíveis mesmo para aquele usuário que não sabe como as atividades foram categorizadas ou qual critério foi adotado na categorização (estrutural ou funcional);

- os termos não adotados pelo sistema, incluídos na mesma ordem alfabética e encaminhando o usuário para o termo adotado, evitando desse modo que fique perdido no labirinto da organização da organização da informação ou ainda que conclua que a informação por ele procurada não está presente, pelo simples fato de ter recorrido a sinônimos no momento da busca. (SMIT; KOBASHI, 2003, p. 46-47, grifo das autoras)

As listas alfabéticas são um instrumento que podem cobrir uma lacuna comum nos planos de classificação e tabelas de temporalidade que é a inexistência de uma ferramenta de identificação dos termos efetivamente utilizados que, normalmente, não aparecem nos instrumentos arquivísticos. A incorporação da lista alfabética, principalmente em instrumentos extensos, colabora com a solução de dúvidas técnicas do arquivista no dia-a-dia de trabalho. Disso decorre a relação simbiótica entre o vocabulário e o plano de classificação. O vocabulário reforça e sustenta a estrutura sistemática presente nos planos de classificação e acrescenta-se uma parte alfabética, a qual é, desde a criação da Encyclopédie de, Diderot e D’Alembert, uma das maneiras mais universais de acesso a uma determinada estrutura de informação.

Por fim, desde o diagnóstico do arquivo e, ao longo da estruturação do vocabulário controlado, é importante trabalhar a questão da cultura organizacional do ponto de vista da percepção do grupo de colaboradores sobre a importância dos termos adotados, visando a consolidação de seu uso e do vocabulário controlado como instrumento de gestão.

Os diagnósticos de arquivo, sem dúvida, precisam ser refletidos, 
discutidos e ampliados, percebeu-se na análise da obra de Pazin (2005) a preocupação de se investigar até mesmo a história da organização, o trâmite documental e informacional e um olhar crítico para os tipos documentais, principais fontes de coletas de informação para o arquivista no momento de realizar o diagnóstico.

Notou-se que pesquisas têm sido realizadas em torno dos vocabulários controlados (PINTO, 2016; FREITAS, SIMIONATO e ALBUQUERQUE, 2015), com intuito de aproximar e consolidar esse instrumento junto à Arquivologia, porém destaca-se a relevância de inseri-lo como uma das etapas do diagnóstico de arquivo, no que tange à análise da linguagem natural, elevando-o a um instrumento imprescindível à GD.

A partir de potencialização de pesquisas, juntamente com discussões da área, julga-se que essas medidas afetam diretamente na consolidação do uso de novos instrumentos e ferramentas que possam agregar em relação ao processo de organização.

Existem maneiras específicas para contribuir com a consolidação, seja de metodologias, ferramentas ou de instrumentos. $O$ incentivo à pesquisa, a discussão na área científica e a aproximação dessas metodologias nas práticas da arquivística proporcionarão que instrumentos sejam absorvidos, principalmente pelas vantagens que podem trazer para 0 processo de organização e recuperação da informação.

\section{CONSIDERAÇÕES FINAIS}

A presente pesquisa proporcionou a reflexão sobre os conceitos e métodos utilizados em diagnóstico de arquivo, com intuito de ampliar a discussão acerca do tema no que tange a inclusão de análise da linguagem natural, visando à construção de vocabulário controlado, instrumento fundamental a GD, uma vez que faz o elo entre usuário-sistema-conteúdo.

O diagnóstico de arquivo é uma atividade arquivística que contribui com todas as demais etapas necessárias para gerir documentos e informações. Porém, muitas vezes, as publicações sobre essa temática perpassam 
experiências empíricas, ou seja, profissionais que tiveram experiências em organizar arquivos e relatam seus resultados. A carência de literatura que trata desse assunto reflete na realização de diagnósticos de arquivos parciais, com resultados pouco duradouros.

Ressalta-se ainda, que o próprio termo diagnóstico de arquivo reflete a complexidade dessa atividade, uma vez que diretamente remete a uma avaliação de estruturas físicas, como prédio, caixas, prateleiras, dentre outros elementos que não abarcam questões informacionais e documentais, relevantes e necessárias para uma implantação de GD.

Sabe-se que a partir do diagnóstico de arquivo é possível a implantação da GD, com seus mais variados instrumentos arquivísticos: plano de classificação, tabela de temporalidade documental, protocolos, dentre outros. Destaca-se que o vocabulário controlado é tão relevante quanto os demais instrumentos citados, no que tange ao gerenciamento documental e informacional, uma vez que seu uso evitará ruídos no acesso à informação: séries documentais com pluralidade de termos, séries documentais que não remetem ao conteúdo, termos vagos, ambiguidades, dentre outras dificuldades existentes, quando não há controle de vocabulário.

Defende-se aqui, que o vocabulário controlado anteceda a elaboração do plano de classificação, uma vez que, se ocorrer dualidade nas séries documentais, o mesmo documento, com a mesma função, pode estar arquivado em locais diferentes, com mais de um nome, dificultando o acesso à informação.

Sendo o vocabulário controlado um instrumento fundamental à GD, sua carência pode, sem dúvida, prejudicar e dificultar a relação usuário-sistemaconteúdo. Os arquivistas precisam dominar os elementos necessários para a construção do vocabulário controlado e utilizá-lo. Identificar os elementos necessários à construção desse instrumento durante a realização do diagnóstico de arquivo contribui com uma GD eficiente, eficaz e perspicaz. 


\section{REFERÊNCIAS}

AGUIAR, F.L; TALÁMO, M.F.G.M. O controle de vocabulário da linguagem orgânico-funcional- concepções e princípios teórico-metodológicos. Acervo. Rio de Janeiro, V.25, n.01, p.117-138, jan/jun 2012.

\section{ALENCAR, M. F. Organização e representação do conhecimento} arquivístico: abordagens para a construção de tesauros funcionais. 2017. Dissertação de Mestrado- Universidade Estadual de Londrina (UEL).

ALMEIDA, M. F. I. DE; VITORIANO, M. C. C. P. Diagnóstico de arquivos e mapeamento da informação: interlocução da gestão documental com a gestão da informação. Em Questão, n. 3, v. 24, p. 68-95, 2018.

AMERICAN NATIONAL STANDARDS INSTITUTE. National Information Standards Organization. ANSI/NISO Z39.19-2005 (R2010) - Guidelines for the construction, format and management of monolingual controlled vocabularies. Bethesda: NISO Press, 2005.

ARANDA, O. F.; RODRÍGUEZ, A. A. R.; MUGICA, M. M. M. Diagnóstico sobre la gestión documental y de archivos en la Universidad Central Marta Abreu de las Villas. Cuba: Caso de estúdio. In: Revista Española de Documentación Científica., 35, 4, octubre-diciembre, 573-598, 2012.

\section{ARQUIVO NACIONAL (Brasil). Dicionário Brasileiro de Terminologia} Arquivística. Rio de Janeiro: Arquivo Nacional, 2005.

BRASCHER, M; CARLAN, E. Sistemas de Organização do conhecimento: antigas e novas linguagens. IN: ROBREDO, J; BRASCHER, M (Org). Passeio pelo Bosque da Informação: estudos sobre a representação e organização da informação e do conhecimento. Brasília-DF: IBICT, 2010.

BRASIL. Lei 8.159, de 08 de janeiro de 1991. Dispõe sobre a política nacional de arquivos públicos e privados e dá outras providências. Diário Oficial da União. Brasília, DF, 28 jan.1991. Disponível em: http://www.planalto.gov. br/ccivil_03/leis/L8159.htm. Acesso em 15 jul. 2020.

BRASIL. CONSELHO NACIONAL DE ARQUIVOS (CONARQ) NOBRADE: Norma Brasileira de Descrição Arquivística. Rio de Janeiro: Arquivo Nacional, 2006.

CAMARGO, A.M.A; BELLOTTO, H. L.: Dicionário de Terminologia Arquivística. São Paulo: Centro de Memória da Educação FEUSP/FAPESP, 2010.

CAVATI SOBRINHO, H; FUJITA, M. S. L. Construção de macroestrutura de categorias de Linguagem Documentária em Economia: proposta de inovação 
metodológica. XII Congreso ISKO España y II Congreso ISKO EspañaPortugal, 19-20 de noviembre, 2015, Organización del conocimiento para sistemas de información abiertos. Murcia: Universidad de Murcia.

CONSELHO INTERNACIONAL DE ARQUIVOS (CIA). ISAAR(CPF): norma internacional de registro de autoridade arquivística para entidades coletivas, pessoas e famílias. 2. ed., Rio de Janeiro: Arquivo Nacional, 2004.

CONSELHO INTERNACIONAL DE ARQUIVOS (CIA) ISAD(G): Norma geral internacional de descrição arquivística: segunda edição, adotada pelo Comitê de Normas de Descrição, Estocolmo, Suécia, 19-22 de setembro de 1999, versão final aprovada pelo CIA. - Rio de Janeiro: Arquivo Nacional, 2000.

DAVANZO, L. Vocabulário controlado para arquivos: análise de viabilidade e proposta. 2016. 102 F. Dissertação (Mestrado). Programa de Pós-Graduação em Ciência da Informação- Faculdade de Filosofia e Ciências, Universidade Estadual Paulista - UNESP, Marília, 2016.

\section{DIEHL, A. A.; TATIM, D. C. Pesquisa em Ciências Sociais Aplicadas:} métodos e técnicas. São Paulo: Pearson Prentice Hall, 2004.

FREITAS, L. M; SIMIONATO, A. C.; ALBUQUERQUE, A. C. A elaboração e uso de vocabulário controlado em sistema de gerenciamento eletrônico de informações arquivísticas: a experiência da Embrapa Soja. In. $4^{\circ}$ Seminário Científico de Arquivologia e Biblioteconomia: do outro lado da informação, 2015, Marília, SP. Seminário Científico Arquivologia e Biblioteconomia. Marília, SP: UNESP, 2015. v. 4.

GIL, A. C. Métodos e técnicas de pesquisa social. $4^{a}$ ed. São Paulo: Atlas, 1994.

HARPRING, P. Introdução aos Vocabulários Controlados: terminologia para arte, arquitetura e outras obras culturais. São Paulo: Secretaria da Cultura do Estado: Pinacoteca. de São Paulo: ACAM Portinari, 2016.

INTERNATIONAL ORGANIZATION FOR STANDARDIZATION. ISO 25964: information and documentation: thesauri and interoperability with other vocabularies - part 1: thesauri for information retrieval. Genebra, 2011.

LOPES, L. C. A gestão da informação: as organizações, os arquivos e a informática aplicada. Rio de Janeiro, 2009.

MOREIRA, W. et al. Vocabulário controlado para a representação documentária em arquivos correntes da UNESP. In: SEMINÁRIO CIENTÍFICO ARQUIVOLOGIA E BIBLIOTECONOMIA, 4., 2015, Marília. Anais[....] Marília: UNESP, 2015. 
NATIONAL ARCHIVES OF AUSTRÁLIA. DEVELOPING A FUNCTIONS THESAURUS: GUIDELINES FOR COMMONWEALTH AGENCIES.

CAMBERRA, 2000.

PAZIN, M. Arquivos de empresas, tipologia documental. São Paulo: Associação de Arquivistas de São Paulo, 2005.

PINTO, M.C. Proposta para a criação de um vocabulário controlado a partir do sistema de informações do Arquivo Nacional do Brasil (SIAN). 2016.

PONJUÁN DANTE, G. Gestão da informação: precisões conceituais a partir de sua origem. Informação \& Informação, [S.I.], v. 13, n. 1esp, p. 26-38, dez. 2008. ISSN 1981-8920. Disponível em:

http://www.uel.br/revistas/uel/index.php/informacao/article/view/1830/1544. Acesso em: 15 jun. 2020.

RODRIGUES, A. C. Identificação como requisito metodológico para a gestão de documentos e acesso a informações na administração pública brasileira. In. Ciência da Informação, Brasília, DF, v. 42 n. 1, p.64-80 jan./abr., 2013. Disponível em: http://revista.ibict.br/ciinf/article/view/1395/1573. Acesso em 03 de abr. de 2020

\section{SMIT, J. W; KOBASHI, N. Y. Como elaborar vocabulário controlado em} arquivos. São Paulo: Arquivo do Estado de São Paulo, 2003.

LOUSADA, M; VALENTIM, M.L.P. A relação entre informação orgânica e gestão documental. In: VALENTIM, M.L.P. (org). Gestão, mediação e uso da informação [online]. São Paulo: Editora UNESP; São Paulo: Cultura Acadêmica, 2010. Disponível em: http://books.scielo.org. Acesso em: 15 jul. 2020.

VALENTIM, M. L. P. Gestão documental em ambientes empresariais. In:

VALENTIM, M. L. P. (org). Estudos Avançados em Arquivologia. Marília:

Oficina universitária: São Paulo: Cultura Acadêmica, 2012.

VITORINI, E. F. Uso da linguagem documentária na busca da informação em bibliotecas universitárias: a perspectiva dos deficientes visuais. Dissertação. Disponível em: http://www.marilia.unesp.br/Home/Pos-

Graduacao/Cienciadalnformacao/Dissertacoes/vitorini_ef_me_mar.pdf. Acesso em: 14 jul. 2020.

\section{IDENTIFICATION OF ELEMENTS FOR CONSTRUCTION OF CONTROLLED VOCABULARY: CONTRIBUTIONS OF RECORDS SURVEY}




\begin{abstract}
Introduction: The organizations have sought the appropriate treatment of their information, this goes through the implementation of records management, through their archival instruments. This research fosters discussions about records survey methodology and the construction of controlled vocabularies, fundamental activities for the implementation of effective records management. It is a problem of this research: what are the elements used during the records survey to preparation of controlled vocabulary? Objective: To point out the necessary elements to identify the natural language while performing records survey for the creation fo controlled vocabulary. Methodology: It was used exploratory research, using a bibliographic review as research procedure, providing a deepening of the object of study. Results: It was obtained as main result that, an inclusion of the analysis of the natural language in the process of records survey is fundamental for the elaboration of controlled vocabulary, as it will suport the other archival instruments. It is also pointed out the elements that make up a controlled vocabulary, how to identify them in the records survey and the products generated from their elaboration. Conclusions: The study demonstrates the importance of fostering and dissemination the need for archivists to make a holistic records survey including the analysis of natural language, performing the construction of controlled vocabularies as a focus on records management.
\end{abstract}

Descriptors: Records management. Records Survey. Natural language. Documentary Language. Controlled Vocabulary.

\title{
IDENTIFICACIÓN DE ELEMENTOS PARA LA CONSTRUCCIÓN DE VOCABULARIO CONTROLADO: CONTRIBUCIONES DEL CENSO DE ARCHIVOS
}

\begin{abstract}
RESUMEN
Introducción: Las organizaciones han estado buscando el tratamiento adecuado de su información, esto va más allá de la implementación de la gestión de documentos a través de sus instrumentos de archivo. Esta investigación fomenta debates sobre la metodología de diagnóstico de archivo y la construcción de vocabulario controlado, actividades fundamentales para la implementación de una gestión de documentos efectiva. El problema de esta investigación es: ¿qué elementos deben identificarse durante el diagnóstico del archivo com el objetivo de elaborar um vocabulário controlado? Objetivo: Señalar los elementos necessários para identificar el lenguage natural durante el diagnóstico del archivo para la elaboración del vocabulário controlado. Metodología: La investigación se caracteriza por ser exploratória y descriptiva, utilizando la revisión bibliográfica como procedimento de investigación, a fim de proporcionar uma mayor profundidad del objeto de estúdio de esta investigación. Resultados: El resultado principal fue que la inclusion del análise del lenguaje natural de la organización em el processo de diagnóstico de archivo es fundamental para el desarrollo de vocabulário controlado, ya que apoyará los otros instrumentos de archivo. También señala los elementos que componen un vocabulario controlado, cómo identificarlos en el diagnóstico de archivo y los productos generados a partir de su elaboración. Conclusiones: Demuestra la importância de promover y difundir la necesidad de que los archiveros lleven a cabo um diagnóstico holístico de archivos que incluya el análisis del lenguage natural, con el objetivo de construir vocabulários
\end{abstract}


Maria Fabiana Izidio de Almeida, Walter Moreira, Luciana Davanzo, Márcia de Carvalho Pazin Vitoriano

Identificação de elementos para construção do vocabulário controlado: contribuições do diagnóstico de arquivo

controlados como foco en la gestión de documentos.

Descriptores: Gestión documental. Censo de archivos. Lenguaje natural. Lenguaje documental. Vocabulario controlado.

Recebido em: 26.10.2020

Aceito em: 04.02.2021 